Editorial

\title{
Recent Advances in Fluid Flow in Fractured Porous Media
}

\author{
Richeng Liu ${ }^{1,2} \mathbb{D}$, Sha Lou ${ }^{3, *}$ and Yujing Jiang ${ }^{2} \mathbb{D}$ \\ 1 State Key Laboratory for Geomechanics and Deep Underground Engineering, China University of Mining \\ and Technology, Xuzhou 221116, China; liuricheng@cumt.edu.cn \\ 2 School of Engineering, Nagasaki University, 1-14 Bunkyo-machi, Nagasaki 8528521, Japan; \\ jiang@nagasaki-u.ac.jp \\ 3 Department of Hydraulic Engineering, Tongji University, Shanghai 200092, China \\ * Correspondence: lousha@tongji.edu.cn; Tel.: +86-21-65989220
}

Received: 28 April 2019; Accepted: 28 April 2019; Published: 2 May 2019

check for updates

The fluid flows through both the fractures and pores in deep-seated rock masses, which is of special importance for the performance of underground facilities such as groundwater use and nuclear waste disposal [1-5]. Many researchers have contributed to modeling fluid flow through pores, fractures, and dual-porosity media, using the developed laboratory experimental systems, theories and numerical methods [6-9]. Although the fluid flow is affected by stresses that always exist deep underground [10-13], we should first understand the hydraulic characteristics of fractured porous media $[14,15]$. How to predict the permeability of a porous media and/or a fracture network, as well as how the interface of pores and fractures influences fluid flow, is still unknown [16,17]. This is our motivation to handle this Special Issue (SI) of Processes, focusing on reporting the recent advances in fluid flow in fractured porous media.

The special issue "Fluid Flow in Fractured Porous Media" has been closed on 31 December 2018, in which a total of 58 papers are collected from different countries and different affiliations. The accepted papers include a wide variety of topics such as granite permeability investigation, grouting, coal mining, roadway, concrete, and so on. In the previous review work [18], we have introduced the contributions of first published 27 papers [19-45] and we will continue to introduce the remaining 31 papers in this study [46-76]. The details are summarized as follows:

(1) Jiang, D. et al., Experimental Investigation on the Law of Grout Diffusion in Fractured Porous Rock Mass and Its Application [46].

This paper investigated the evolutions of grout diffusion in fractured porous rock masses using a developed visualization platform and a three-dimensional grouting experimental system. The results show that a parabolic shape exists when the grout flows from the hole to the bottom of the model. The grouting pressure has a larger influence on the grouting diffusion radius than the water-cement ratio.

(2) Qiu, Z. et al., Rheological Behavior and Modeling of a Crushed Sandstone-Mudstone Particle Mixture [47].

This paper presented the rheological deformation of a sandstone-mudstone particle mixture through confined uniaxial compressive tests using 24 samples. The results show that with increasing the uniaxial compressive, the rheological process experiences four stages: Linear stage, attenuation rheological stage, secondary attenuation rheological stage, and stable stage. The authors proposed a segmented rheological model for a coarse-grained soil.

(3) Yang, X. et al., Effect of Dry-Wet Cycling on the Mechanical Properties of Rocks: A Laboratory-Scale Experimental Study [48]. 
This paper experimentally depicted the effect of dry-wet cycling on mechanical properties of rocks in a lab-scale. The results show that the uniaxial compressive strength decreases by a rate of $34.21 \%$ and the elastic modulus decreases by a rate of $44.63 \%$ when the wet-cycle number increases from $0-15$. The dry-wet cycling has a significant influence on the distributions of particle size and pore structure.

(4) Zhang, Z. et al., Changes in Particle Size Composition under Seepage Conditions of Reclaimed Soil in Xinjiang, China [49].

This paper used the geotechnical experimental method to investigate the changes in particle size composition of reclaimed soil in Xinjiang, China. The results show that the granulometric composition of the reclaimed soil changes dramatically with varying depths from $10 \mathrm{~m}-70 \mathrm{~m}$. For a depth of $10 \mathrm{~m}$, the granulometric composition is similar with that of undisturbed reclaimed soil; while when the depth is $70 \mathrm{~m}$, the fine particle content is greatly different with that of undisturbed reclaimed soil.

(5) Irfan, M. et al., Geotechnical Properties of Effluent-Contaminated Cohesive Soils and Their Stabilization Using Industrial By-Products [50].

This paper reported the chemical impact of dyeing and tannery on high plastic clay and low plastic clay, and examined the time-dependent variations in the properties at different effluent percentages. The results show that with increasing time upon dyeing contamination, the unconfined compressive strength of both soils increases.

(6) Zhang, M. et al., High Mixing Efficiency by Modulating Inlet Frequency of Viscoelastic Fluid in Simplified Pore Structure [51].

This paper proposed an effective mixing approach to simulate the mixing of viscoelastic fluids flowing through a simplified pore T-junction model. The results show that the mixing degree is relatively low, i.e., 0.15 for Newtonian fluid and 0.25 for viscoelastic fluid, under a constant driving pressure. When the phase difference is $180^{\circ}$, the mixing degree has a maximum value of 0.82 for the viscoelastic fluid.

(7) Liu, S. et al., Experimental Development Process of a New Fluid-Solid Coupling Similar-Material Based on the Orthogonal Test [52].

This paper developed a new fluid-solid coupling similar material, which is mixed using river sand, calcium carbonate, talc powder, white cement, Vaseline, and antiwear hydraulic oil. The results indicate that the selected raw materials and proportioning method are suitable for usage in a coal mine floor water inrush.

(8) Liu, L. et al., The Impact of Oriented Perforations on Fracture Propagation and Complexity in Hydraulic Fracturing [53].

This paper developed a fully coupled FEM-based hydro-mechanical model to understand the interaction between hydraulic fracture and oriented perforation. Here, FEM represents the finite element method. The results show that when the perforation azimuth from the direction of the maximum principal stress is larger, the curvature of the fracture during hydraulic fracture reorientation is larger. For the liquid-based hydraulic fracturing, an increase in liquid viscosity from $10^{-3} \mathrm{~Pa} \cdot \mathrm{s}-1 \mathrm{~Pa} \cdot \mathrm{s}$ increases the critical perforation angle from $70^{\circ}-80^{\circ}$.

(9) Wang, F. et al., Experimental Study on Feasibility of Enhanced Gas Recovery through $\mathrm{CO}_{2}$ Flooding in Tight Sandstone Gas Reservoirs [54].

This paper studied the feasibility of enhanced gas recovery through $\mathrm{CO}_{2}$ flooding in tight sandstone gas reservoirs. The results show that the $\mathrm{CO}_{2}$ flooding increases the gas recovery by a rate of $18.36 \%$ with respect to the depletion development method. A significant influence is observed from the presence of a dip angle in tight sandstone gas reservoirs. 
(10) Zhuo, Q. et al., The Effect of Collision Angle on the Collision and Adhesion Behavior of Coal Particles and Bubbles [55].

This paper exhibited the effect of collision angle on collision and adhesion behaviors of coal particles and bubbles. The results show that with the increment of collision angle, the distribution ranges of initial settlement position and particle central distribution interval expands outward. The resistance layer influences the velocity of particles and the collision angle affects the adhesion efficiency significantly.

(11) Wang, H. et al., Feasibility of Using Gangue and Fly Ash as Filling Slurry Materials [56].

In this paper, gangue and fly ash samples are used as filling materials through tests on the optimal ratio of the slurry components using an Intelligent Torque Rheometer. The results show that the optimal slurry composition of coal gangue, fly ash and gelling agent should have a weight ratio of 8:3:1. The paste-like slurry can effectively reduce the surface subsidence.

(12) Huang, S. et al., Effects of Cyclic Wetting-Drying Conditions on Elastic Modulus and Compressive Strength of Sandstone and Mudstone [57].

This paper investigated the effect of wet-dry cycling on the evolutions of elastic modulus and compressive strengths of sandstone and mudstone. The results show that the larger the number of wet-dry cycling, the smaller the values of both elastic modulus and uniaxial compressive strength of sandstone and mudstone. The mechanical properties have a linear relationship with the porosity.

(13) Zhang, Y. et al., Experimental Study on Compression Deformation and Permeability Characteristics of Grading Broken Gangue under Stress [58].

This paper experimentally studied the compression deformations and permeability of grading broken gangue under stresses. The results show that the stress of broken gangue has an exponential relationship with the strain, and the compression modulus is positively correlated with the compression rate. It is more difficult to compress for the samples with discontinuous grading than the continuous grading samples.

(14) Sun, X. et al., Investigation of Deep Mine Shaft Stability in Alternating Hard and Soft Rock Strata Using Three-Dimensional Numerical Modeling [59].

This paper used the geological strength index (GSI) method to characterize the deformation and stress of surrounding rocks and the shaft lining under soft and hard strata in Anju coal mine, Shandong Province, China. The results show that when the shaft is excavated without supports, the shear failure and tensile failure occur in shallow surrounding rock shafts. The maximum shear stress and plastic zone appear around the interface between the soft and hard rocks.

(15) Huang, M. et al., 2D Plane Strain Consolidation Process of Unsaturated Soil with Vertical Impeded Drainage Boundaries [60].

This paper estimated the 2D plane strain consolidation processes of unsaturated soils under vertical impeded drainage boundaries. The results show that the time domain can be efficiently calculated using the numerical inversion of the Laplace transform. The semi-analytical solutions agree well with the different solutions and the solutions reported in the literature.

(16) Wei, P. et al., Characterization of Pores and Fractures in Soft Coal from the No. 5 Soft Coalbed in the Chenghe Mining Area [61]. 
This paper explored the pore structure characteristics of soft coal masses using a mercury intrusion method, low-temperature liquid nitrogen adsorption, and scanning electron microscopy (SEM). The results show that the mercury-injection and mercury-ejection curves of soft coals have significant differences, while those of hard coals are very close. This indicates that in the soft coal, the pores are mainly open while in the hard coal, the pores are commonly closed. Besides, the fractal dimension of soft coals, which is used for characterizing pore distributions, is larger than that of hard coals.

(17) Li, J. et al., Numerical Investigation of Hydraulic Fracture Propagation Based on Cohesive Zone Model in Naturally Fractured Formations [62].

This paper numerically investigated the hydraulic fracture propagation in naturally fractured formations on the basis of a cohesive zone model. The results show that the stress interference from multiple clusters plays an important role in the suppression and diversion of the fracture network. A lower stress difference is more effective to open the natural fractures than a larger stress difference.

(18) Sun, Z. et al., Simulating the Filtration Effects of Cement-Grout in Fractured Porous Media with the 3D Unified Pipe-Network Method [63].

This paper simulated the filtration effect of cement-grout in fractured porous media using a 3D unified pipe network method. The grout is assumed to exhibit two-phase flow and the filtration effect depends on the concentration and rheology of the grout, and porosity and permeability of the fractured porous media. The results show that the size of the grout penetration region has a limited effect due to the filtration.

(19) Hou, Y. et al., Study on the Preparation and Hydration Properties of a New Cementitious Material for Tailings Discharge [64].

This paper developed a new cement-based material with blast furnace slag to replace the ordinary Portland cement. The mechanical properties are tested using uniaxial compressive strength, $\mathrm{X}$-ray diffraction, and thermal gravity, scanning electron microscope, and mercury intrusion porosimetry experiments. The results show that the mercury intrusion volume is decreased by $18 \%$ and $13 \%$, and the most common pore size is decreased by $53 \%$ and $29 \%$, for the samples manufactured using the new cement-based material and the ordinary Portland cement, respectively.

(20) Wang, C. et al., Experimental Study on the Shear-Flow Coupled Behavior of Tension Fractures Under Constant Normal Stiffness Boundary Conditions [65].

This paper carried out a series of tests to study the shear-flow coupled behaviors of tensile fractures under constant normal stiffness conditions using a sever-controlled direct shearing apparatus. The results show that with increasing the initial normal stress and/or the fracture surface roughness, the peak shear stress increases. The surface roughness of fractures also increases residual shear stress. The larger normal stiffness leads to a larger normal stress and a smaller normal displacement during shearing.

(21) Hao, J. et al., The Effects of Backfill Mining on Strata Movement Rule and Water Inrush: A Case Study [66].

This paper estimated the effect of backfill mining on strata movement and water inrush on the basis of a case study in Caozhuang coal mine, China. The results show that the backfill mining changes the deformation and amplitude of overburden and improves the ground pressure environment. The floor failure depth is much smaller in backfill mining, compared with that in traditional longwall mining.

(22) Hua, W. et al., Experimental Study on Mixed Mode Fracture Behavior of Sandstone under Water-Rock Interactions [67]. 
This paper studied the mechanical properties of sandstones under periodic water-rock interactions using central-cracked Brazilian disk specimens. The results show that the fracture resistance of sandstone is significantly influenced by the periodic water-rock interactions. The cyclic wetting-drying plays a more significant role on the fracture resistance of sandstones than the long-term immersion.

(23) Li, H. et al., Seepage Characteristics and Its Control Mechanism of Rock Mass in High-Steep Slopes [68].

This paper reviewed the up-to-date status of seepage characteristic evolutions of fractured rock masses from lab-scale to the engineering scale. The experimental findings and newly developed numerical techniques on the nonlinear flow regimes of fluid were introduced and discussed in detail. Finally, the authors outlined the scientific progress in fractured rock seepage control theory and optimal design technologies of high-steep slope engineering.

(24) Li, Z. et al., Experimental Study on Electric Potential Response Characteristics of Gas-Bearing Coal During Deformation and Fracturing Process [69].

This paper designed a test system to estimate the evolutions of multi-parameters of gas-bearing colas under loading, which was then used to investigate the electrical potential responses during the deformation and fracturing. The results show that as the gas pressure increases, the confining action and the erosion effect are promoted. When the coal is cracked/damaged, the electrical potential dramatically increases to its maximum value.

(25) Liu, R. et al., Model for the Patterns of Salt-Spray-Induced Chloride Corrosion in Concretes under Coupling Action of Cyclic Loading and Salt Spray Corrosion [70].

This paper experimentally studied the patterns of chloride ion erosion of unsaturated concrete, which subjected to a coupling effect of cyclic loading and salt spray corrosion. The Fick's second law was used to obtain the chloride diffusion coefficient by fitting the variation patterns of chloride concentration. The results show that the porosities of concrete with $30 \%$ fly ash and $20 \%$ mineral powder under three cyclic loading protocols of $50 \%, 65 \%$, and $80 \%$ of the compression strength are $3.49 \%, 3.83 \%$, and $4.71 \%$, respectively.

(26) Qiao, S. et al., The Application of a Three-Dimensional Deterministic Model in the Study of Debris Flow Prediction Based on the Rainfall-Unstable Soil Coupling Mechanism [71].

This paper reported a three-dimensional deterministic model to study the debris flow prediction based on the rainfall-unstable soil coupling mechanism. The results show that the proposed method is suitable for forecasting debris flows at the regional scale, and the application of the Scoops3D model can more efficiently characterize the slope stability than traditional two-dimensional models.

(27) Yu, W. et al., Development of 3D Finite Element Method for Non-Aqueous Phase Liquid Transport in Groundwater as Well as Verification [72].

This paper developed a 3D finite element method to simulate non-aqueous phase liquid transport in groundwater and verified its validity. In the proposed model, the weak form of mass balance equations for water was discretized in space using the Galerkin finite element method. The authors also adopted the mixed form formulations using both pressure water head and water saturation. The developed model can be used for preliminary evaluation of the migration and diffusion of non-aqueous liquid pollution in the fields.

(28) Liu, D. et al., Experimental Investigation of Pore Structure and Movable Fluid Traits in Tight Sandstone [73]. 
This paper reported the variations in pore structures and movable fluid traits in tight sandstones through direction observations, indirect measurements, and imaging processing techniques. The results show that the decreasing rate of water saturation in macropores is larger than that in tiny pores. The sandstones having a poor reservoir quality do not exhibit a remarkable descending of lower limits of movable pore radius.

(29) Wang, X. et al., Experimental Development of Coal-Like Material with Solid-Gas Coupling for Quantitative Simulation Tests of Coal and Gas Outburst Occurred in Soft Coal Seams [74].

This paper developed coal-like materials with solid-gas coupling for quantitative simulation tests. The results show that the ratio of gypsum to petrolatum plays a dominant role on the density, compressive strength, elastic modulus, cohesion and deformation characteristics. The gas adsorption/desorption is controlled by the coal powder content. Finally, an empirical function is proposed to estimate the adsorption capacity.

(30) Zhang, S. et al., DEM Investigation of the Influence of Minerals on Crack Patterns and Mechanical Properties of Red Mudstone [75].

This paper studied the effect of minerals on crack propagation patterns and mechanical properties of red mudstones, based on numerical simulations using the discrete element method (DEM) modeling techniques. The results show that with the increases in circle size of the central mineral and/or mineral ratio, both the elastic modulus and uniaxial compression strength of the model increase. The mineral, which is located in the crack propagation paths, can effectively change the crack propagation direction.

(31) Huang, B. et al., Effect of Nitric Acid Modification on Characteristics and Adsorption Properties of Lignite [76].

This paper depicted the influence of nitric acid modification on pore structures and surface properties of lignite. The results show that nitric acid modification can help lignite adsorb $\mathrm{Pb}^{2+}$. The nitric acid treatment increases the contents of polar oxygen-containing functional groups, including hydroxyl, carbonyl, and carboxyl groups on the surface of lignite.

Finally, we would like to thank all the authors for their valuable contributions, all the reviewers for their comments that greatly improved the quality of the papers and all the editors from the editorial office for their substantial support for us to handle this Special Issue.

Funding: This research, as well as the APC, was funded by National Natural Science Foundation of China, China (Grant No. 51709260) and the Fundamental Research Funds of State Key Laboratory for Geomechanics and Deep Underground Engineering, China University of Mining and Technology, China (Grant No. Z18011).

Conflicts of Interest: The authors declare no conflict of interest.

\section{References}

1. MacMinn, C.; Szulczewski, M.; Juanes, R. $\mathrm{CO}_{2}$ migration in saline aquifers. Part 1. Capillary trapping under slope and groundwater flow. J. Fluid Mech. 2010, 662, 329-351. [CrossRef]

2. Wei, W.; Xia, Y. Geometrical, fractal and hydraulic properties of fractured reservoirs: A mini-review. Adv. Geo-Energy Res. 2017, 1, 31-38. [CrossRef]

3. Gerritsen, M.; Durlofsky, L. Modeling fluid flow in oil reservoirs. Annu. Rev. Fluid Mech. 2005, 37, $211-238$. [CrossRef]

4. Haugen, A.; Fernø, M.; Graue, A.; Bertin, H. Experimental study of foam flow in fractured oil-wet limestone for enhanced oil recovery. SPE Reserv. Eval. Eng. 2012, 15, 218-228. [CrossRef]

5. Grant, M.; Donaldson, I.; Bixley, P. Geothermal Reservoir Engineering; Academic Press: New York, NY, USA, 1983.

6. Huang, N.; Liu, R.; Jiang, Y.; Cheng, Y.; Li, B. Shear-flow coupling characteristics of a three-dimensional discrete fracture network-fault (3D DFN-fault) model considering stress-induced aperture variations. J. Hydrol. 2019, 571, 416-424. [CrossRef] 
7. Liu, R.; Li, B.; Jiang, Y.; Yu, L. A numerical approach for assessing effects of shear on equivalent permeability and nonlinear flow characteristics of 2-D fracture networks. Adv. Water Resour. 2018, 111, 289-300. [CrossRef]

8. Mora, P.; Wang, Y.; Alonso-Marroquin, F. Lattice solid/Boltzmann microscopic model to simulate solid/fluid systems-A tool to study creation of fluid flow networks for viable deep geothermal energy. J. Earth Sci. 2015, 26, 11-19. [CrossRef]

9. Long, J.; Remer, J.; Wilson, C.; Witherspoon, P. Porous media equivalents for networks of discontinuous fractures. Water Resour. Res. 1982, 18, 645-658. [CrossRef]

10. Yang, S.; Huang, Y.; Jing, H.; Liu, X. Discrete element modeling on fracture coalescence behavior of red sandstone containing two unparallel fissures under uniaxial compression. Eng. Geol. 2014, 178, $28-48$. [CrossRef]

11. Yang, S.; Liu, X.; Jing, H. Experimental investigation on fracture coalescence behavior of red sandstone containing two unparallel fissures under uniaxial compression. Int. J. Rock Mech. Min. Sci. 2013, 63, 82-92. [CrossRef]

12. Yang, S.; Yang, D.; Jing, H.; Li, Y.; Wang, S. An experimental study of the fracture coalescence behaviour of brittle sandstone specimens containing three fissures. Rock Mech. Rock Eng. 2012, 45, 563-582. [CrossRef]

13. Yang, S. Crack coalescence behavior of brittle sandstone samples containing two coplanar fissures in the process of deformation failure. Eng. Fract. Mech. 2011, 78, 3059-3081. [CrossRef]

14. Chen, Y.; Hu, S.; Hu, R.; Zhou, C. Estimating hydraulic conductivity of fractured rocks from high-pressure packer tests with an Izbash's law-based empirical model. Water Resour. Res. 2015, 51, 2096-2118. [CrossRef]

15. Zhou, J.; Hu, S.; Fang, S.; Chen, Y.; Zhou, C. Nonlinear flow behavior at low Reynolds numbers through rough-walled fractures subjected to normal compressive loading. Int. J. Rock Mech. Min. Sci. 2015, 80, 202-218. [CrossRef]

16. Yin, Q.; Ma, G.; Jing, H.; Wang, H.; Su, H.; Wang, Y.; Liu, R. Hydraulic properties of 3D rough-walled fractures during shearing: An experimental study. J. Hydrol. 2018, 555, 169-184. [CrossRef]

17. Zhao, Z.; Jing, L.; Neretnieks, I. Evaluation of hydrodynamic dispersion parameters in fractured rocks. J. Rock Mech. Geotech. Eng. 2010, 2, 243-254. [CrossRef]

18. Liu, R.; Jiang, Y. Special Issue: Fluid Flow in Fractured Porous Media. Processes 2018, 6, 178. [CrossRef]

19. He, L.; Yin, Q.; Jing, H. Laboratory Investigation of Granite Permeability after High-Temperature Exposure. Processes 2018, 6, 36. [CrossRef]

20. Jin, Y.; Han, L.; Meng, Q.; Ma, D.; Han, G.; Gao, F.; Wang, S. Experimental Investigation of the Mechanical Behaviors of Grouted Sand with UF-OA Grouts. Processes 2018, 6, 37. [CrossRef]

21. Yan, S.; Liu, T.; Bai, J.; Wu, W. Key Parameters of Gob-Side Entry Retaining in a Gassy and Thin Coal Seam with Hard Roof. Processes 2018, 6, 51. [CrossRef]

22. Li, J.; Huang, Y.; Qiao, M.; Chen, Z.; Song, T.; Kong, G.; Gao, H.; Guo, L. Effects of Water Soaked Height on the Deformation and Crushing Characteristics of Loose Gangue Backfill Material in Solid Backfill Coal Mining. Processes 2018, 6, 64. [CrossRef]

23. Liu, J.; Wan, Z.; Xie, Q.; Li, C.; Liu, R.; Cheng, M.; Han, B. Investigation on Reinforcement and Lapping Effect of Fracture Grouting in Yellow River Embankment. Processes 2018, 6, 75. [CrossRef]

24. Ma, C.; Wang, P.; Jiang, L.; Wang, C. Deformation and Control Countermeasure of Surrounding Rocks for Water-Dripping Roadway below a Contiguous Seam Goaf. Processes 2018, 6, 77. [CrossRef]

25. Liu, R.; Liu, H.; Sha, F.; Yang, H.; Zhang, Q.; Shi, S.; Zheng, Z. Investigation of the Porosity Distribution, Permeability, and Mechanical Performance of Pervious Concretes. Processes 2018, 6, 78. [CrossRef]

26. Xie, X.; Liu, J.; Han, B.; Li, H.; Li, Y.; Li, X. Critical Hydraulic Gradient of Internal Erosion at the Soil-Structure Interface. Processes 2018, 6, 92. [CrossRef]

27. Cui, Y.; Lu, B.; Wu, M.; Luo, W. A New Pseudo Steady-State Constant for a Vertical Well with Finite-Conductivity Fracture. Processes 2018, 6, 93. [CrossRef]

28. Li, Z.; Li, L.; Zhang, Z.; Li, M.; Zhang, L.; Huang, B.; Tang, C. The Fracturing Behavior of Tight Glutenites Subjected to Hydraulic Pressure. Processes 2018, 6, 96. [CrossRef]

29. Chen, S.; Zhang, D.; Shang, T.; Meng, T. Experimental Study of the Microstructural Evolution of Glauberite and Its Weakening Mechanism under the Effect of Thermal-Hydrological-Chemical Coupling. Processes 2018, 6, 99. [CrossRef]

30. Zhu, D.; Jing, H.; Yin, Q.; Han, G. Experimental Study on the Damage of Granite by Acoustic Emission after Cyclic Heating and Cooling with Circulating Water. Processes 2018, 6, 101. [CrossRef] 
31. Chen, Y.; Li, X.; Li, B. Coal Anisotropic Sorption and Permeability: An Experimental Study. Processes 2018, 6, 104. [CrossRef]

32. Zhang, Q.; Li, X.; Bai, B.; Hu, S.; Shi, L. Effect of Pore Fluid Pressure on the Normal Deformation of a Matched Granite Joint. Processes 2018, 6, 107. [CrossRef]

33. Chen, Y.; Qiu, Z.; Li, B.; Yang, Z. Numerical Simulation on the Dynamic Characteristics of a Tremendous Debris Flow in Sichuan, China. Processes 2018, 6, 109. [CrossRef]

34. Sha, Z.; Pu, H.; Li, M.; Cao, L.; Liu, D.; Ni, H.; Lu, J. Experimental Study on the Creep Characteristics of Coal Measures Sandstone under Seepage Action. Processes 2018, 6, 110. [CrossRef]

35. Zhou, L.; Wang, Y.; Feng, D. A High-Order Numerical Manifold Method for Darcy Flow in Heterogeneous Porous Media. Processes 2018, 6, 111. [CrossRef]

36. Wang, S.; Li, H.; Li, D. Numerical Simulation of Hydraulic Fracture Propagation in Coal Seams with Discontinuous Natural Fracture Networks. Processes 2018, 6, 113. [CrossRef]

37. Liu, W.; Zhao, J.; Nie, R.; Liu, Y.; Du, Y. A Coupled Thermal-Hydraulic-Mechanical Nonlinear Model for Fault Water Inrush. Processes 2018, 6, 120. [CrossRef]

38. Xu, S.; Li, C.; Liu, J.; Bian, M.; Wei, W.; Zhang, H.; Wang, Z. Deformation and Hydraulic Conductivity of Compacted Clay under Waste Differential Settlement. Processes 2018, 6, 123. [CrossRef]

39. Xue, D.; Zhou, J.; Liu, Y.; Zhang, S. A Strain-Based Percolation Model and Triaxial Tests to Investigate the Evolution of Permeability and Critical Dilatancy Behavior of Coal. Processes 2018, 6, 127. [CrossRef]

40. Li, Z.; Li, S.; Liu, H.; Zhang, Q.; Liu, Y. Experimental Study on the Reinforcement Mechanism of Segmented Split Grouting in a Soft Filling Medium. Processes 2018, 6, 131. [CrossRef]

41. Zhang, C.; Yu, L.; Feng, R.; Zhang, Y.; Zhang, G. A Numerical Study of Stress Distribution and Fracture Development above a Protective Coal Seam in Longwall Mining. Processes 2018, 6, 146. [CrossRef]

42. Wu, Q.; Wu, Q.; Xue, Y.; Kong, P.; Gong, B. Analysis of Overlying Strata Movement and Disaster-Causing Effects of Coal Mining Face under the Action of Hard Thick Magmatic Rock. Processes 2018, 6, 150. [CrossRef]

43. Zhao, C.; Zhang, R.; Zhang, Q.; Shi, Z.; Yu, S. Shear-Flow Coupled Behavior of Artificial Joints with Sawtooth Asperities. Processes 2018, 6, 152. [CrossRef]

44. Dou, Z.; Sleep, B.; Mondal, P.; Guo, Q.; Wang, J.; Zhou, Z. Temporal Mixing Behavior of Conservative Solute Transport through 2D Self-Affine Fractures. Processes 2018, 6, 158. [CrossRef]

45. Yang, X.; Jing, H.; Qiao, W. Numerical Investigation of the Failure Mechanism of Transversely Isotropic Rocks with a Particle Flow Modeling Method. Processes 2018, 6, 171. [CrossRef]

46. Jiang, D.; Cheng, X.; Luan, H.; Wang, T.; Zhang, M.; Hao, R. Experimental Investigation on the Law of Grout Diffusion in Fractured Porous Rock Mass and Its Application. Processes 2018, 6, 191. [CrossRef]

47. Qiu, Z.; Cao, T.; Li, Y.; Wang, J.; Chen, Y. Rheological Behavior and Modeling of a Crushed Sandstone-Mudstone Particle Mixture. Processes 2018, 6, 192. [CrossRef]

48. Yang, X.; Wang, J.; Hou, D.; Zhu, C.; He, M. Effect of Dry-Wet Cycling on the Mechanical Properties of Rocks: A Laboratory-Scale Experimental Study. Processes 2018, 6, 199. [CrossRef]

49. Zhang, Z.; Sui, W.; Wang, K.; Tang, G.; Li, X. Changes in Particle Size Composition under Seepage Conditions of Reclaimed Soil in Xinjiang, China. Processes 2018, 6, 201. [CrossRef]

50. Irfan, M.; Chen, Y.; Ali, M.; Abrar, M.; Qadri, A.; Bhutta, O. Geotechnical Properties of Effluent-Contaminated Cohesive Soils and Their Stabilization Using Industrial By-Products. Processes 2018, 6, 203. [CrossRef]

51. Zhang, M.; Cui, Y.; Cai, W.; Wu, Z.; Li, Y.; Li, F.; Zhang, W. High Mixing Efficiency by Modulating Inlet Frequency of Viscoelastic Fluid in Simplified Pore Structure. Processes 2018, 6, 210. [CrossRef]

52. Liu, S.; Liu, W. Experimental Development Process of a New Fluid-Solid Coupling Similar-Material Based on the Orthogonal Test. Processes 2018, 6, 211. [CrossRef]

53. Liu, L.; Li, L.; Elsworth, D.; Zhi, S.; Yu, Y. The Impact of Oriented Perforations on Fracture Propagation and Complexity in Hydraulic Fracturing. Processes 2018, 6, 213. [CrossRef]

54. Wang, F.; Liu, Y.; Hu, C.; Wang, Y.; Shen, A.; Liang, S. Experimental Study on Feasibility of Enhanced Gas Recovery through $\mathrm{CO}_{2}$ Flooding in Tight Sandstone Gas Reservoirs. Processes 2018, 6, 214. [CrossRef]

55. Zhuo, Q.; Liu, W.; Xu, H.; Sun, X.; Zhang, H.; Liu, W. The Effect of Collision Angle on the Collision and Adhesion Behavior of Coal Particles and Bubbles. Processes 2018, 6, 218. [CrossRef]

56. Wang, H.; Jiao, J.; Wang, Y.; Du, W. Feasibility of Using Gangue and Fly Ash as Filling Slurry Materials. Processes 2018, 6, 232. [CrossRef] 
57. Huang, S.; Wang, J.; Qiu, Z.; Kang, K. Effects of Cyclic Wetting-Drying Conditions on Elastic Modulus and Compressive Strength of Sandstone and Mudstone. Processes 2018, 6, 234. [CrossRef]

58. Zhang, Y.; Zhou, W.; Li, M.; Chen, Z. Experimental Study on Compression Deformation and Permeability Characteristics of Grading Broken Gangue under Stress. Processes 2018, 6, 257. [CrossRef]

59. Sun, X.; Li, G.; Zhao, C.; Liu, Y.; Miao, C. Investigation of Deep Mine Shaft Stability in Alternating Hard and Soft Rock Strata Using Three-Dimensional Numerical Modeling. Processes 2019, 7, 2. [CrossRef]

60. Huang, M.; Li, D. 2D Plane Strain Consolidation Process of Unsaturated Soil with Vertical Impeded Drainage Boundaries. Processes 2019, 7, 5. [CrossRef]

61. Wei, P.; Liang, Y.; Zhao, S.; Peng, S.; Li, X.; Meng, R. Characterization of Pores and Fractures in Soft Coal from the No. 5 Soft Coalbed in the Chenghe Mining Area. Processes 2019, 7, 13. [CrossRef]

62. Li, J.; Dong, S.; Hua, W.; Li, X.; Pan, X. Numerical Investigation of Hydraulic Fracture Propagation Based on Cohesive Zone Model in Naturally Fractured Formations. Processes 2019, 7, 28. [CrossRef]

63. Sun, Z.; Yan, X.; Han, W.; Ma, G.; Zhang, Y. Simulating the Filtration Effects of Cement-Grout in Fractured Porous Media with the 3D Unified Pipe-Network Method. Processes 2019, 7, 46. [CrossRef]

64. Hou, Y.; Ding, P.; Han, D.; Zhang, X.; Cao, S. Study on the Preparation and Hydration Properties of a New Cementitious Material for Tailings Discharge. Processes 2019, 7, 47. [CrossRef]

65. Wang, C.; Jiang, Y.; Luan, H.; Liu, J.; Sugimoto, S. Experimental Study on the Shear-Flow Coupled Behavior of Tension Fractures Under Constant Normal Stiffness Boundary Conditions. Processes 2019, 7, 57. [CrossRef]

66. Hao, J.; Shi, Y.; Lin, J.; Wang, X.; Xia, H. The Effects of Backfill Mining on Strata Movement Rule and Water Inrush: A Case Study. Processes 2019, 7, 66. [CrossRef]

67. Hua, W.; Li, J.; Dong, S.; Pan, X. Experimental Study on Mixed Mode Fracture Behavior of Sandstone under Water-Rock Interactions. Processes 2019, 7, 70. [CrossRef]

68. Li, H.; Tian, H.; Ma, K. Seepage Characteristics and Its Control Mechanism of Rock Mass in High-Steep Slopes. Processes 2019, 7, 71. [CrossRef]

69. Li, Z.; Niu, Y.; Wang, E.; Liu, L.; Wang, H.; Wang, M.; Ali, M. Experimental Study on Electric Potential Response Characteristics of Gas-Bearing Coal During Deformation and Fracturing Process. Processes 2019, 7, 72. [CrossRef]

70. Liu, R.; Yin, H.; Zhang, L.; Li, B.; Mao, X. Model for the Patterns of Salt-Spray-Induced Chloride Corrosion in Concretes under Coupling Action of Cyclic Loading and Salt Spray Corrosion. Processes 2019, $7,84$. [CrossRef]

71. Qiao, S.; Qin, S.; Chen, J.; Hu, X.; Ma, Z. The Application of a Three-Dimensional Deterministic Model in the Study of Debris Flow Prediction Based on the Rainfall-Unstable Soil Coupling Mechanism. Processes 2019, 7, 99. [CrossRef]

72. Yu, W.; Li, H. Development of 3D Finite Element Method for Non-Aqueous Phase Liquid Transport in Groundwater as Well as Verification. Processes 2019, 7, 116. [CrossRef]

73. Liu, D.; Sun, W.; Ren, D. Experimental Investigation of Pore Structure and Movable Fluid Traits in Tight Sandstone. Processes 2019, 7, 149. [CrossRef]

74. Wang, X.; Xie, W.; Su, Z.; Tang, Q. Experimental Development of Coal-Like Material with Solid-Gas Coupling for Quantitative Simulation Tests of Coal and Gas Outburst Occurred in Soft Coal Seams. Processes 2019, 7, 155. [CrossRef]

75. Zhang, S.; Zhang, D.; Zhao, Q.; Chi, M.; Zhang, W.; Yu, W. DEM Investigation of the Influence of Minerals on Crack Patterns and Mechanical Properties of Red Mudstone. Processes 2019, 7, 162. [CrossRef]

76. Huang, B.; Liu, G.; Wang, P.; Zhao, X.; Xu, H. Effect of Nitric Acid Modification on Characteristics and Adsorption Properties of Lignite. Processes 2019, 7, 167. [CrossRef]

(C) 2019 by the authors. Licensee MDPI, Basel, Switzerland. This article is an open access article distributed under the terms and conditions of the Creative Commons Attribution (CC BY) license (http://creativecommons.org/licenses/by/4.0/). 